\title{
The design of the warehouse layout based on the non-logistics analysis of SLP
}

\author{
Yifei Zhang ${ }^{1}$ \\ ${ }^{1}$ Industrial Engineering, School of Economics and Management, Beijing JiaoTong University, Beijing, China
}

\begin{abstract}
Using SLP method obtains the comprehensive correlation through the analysis of the logistics relationship and non-logistics relationship between the various operating units of the warehouse. According to the current situation of the comprehensive related relationship and the warehouse problem, designers can formulate a feasible plan. However, owing to the SLP method is insufficient in solving the problem of facility layout, that is, it is easy to be influenced by the subjective factors of the designer, especially in analyzing the non-logistic relationship. In this paper, the non-logistics relationship determination process is quantified, and ultimately improved scheme.
\end{abstract}

\section{INTRODUCTION}

In modern enterprises, warehouses are a transit area for connection purchase, production and sales, and compared with the traditional warehouses, modern warehouses more focus on profits. Therefore, the modern warehouse has begun as a whole system, which pays more attention to its overall operation effect, regardless of the transportation process, storage mode or layout design and are beginning to pay attention to the reasonable division of work units, the reasonable layout of the work unit location design, shelf distribution mode and the maximum height of items which can be stacked. Through the improvement of the warehouse facilities, we can improve the storage capacity of the warehouse and the efficiency of the workers. In the process of enterprise operation, warehouse plays an important role, to a certain extent, and affects the average productivity of society, so the warehouse facility planning has economic research significance [1]. This paper will carry out planning and design of the warehouse, improving the actual operation of the warehouse problems. However, there is a strong subjective initiative in the SLP method, the non-logistics relationship determination process is quantified, and ultimately improved scheme to increased storage capacity and productivity [2].

\section{NON-LOISTICS RELATIONSHIP QUANTIFICATION OF SLP}

When the SLP method is used to analyze the non-logistics relationship between the operation units, it depends on several evaluation indicators, and in the process of determining the degree of correlation between non-logistics relations, the subjective idea of the designer has to be mixed, so the objectivity of the results is affected. Non-logistics relationships are improved by quantitative analysis [3]. Here are the steps:

(1) According to the access to data and the actual situation of the warehouse, it is to determine non-logistics evaluation factors.

(2) Through the questionnaire, the warehouse staff, delivery personnel, factory management personnel sort the importance of these evaluators. The higher the ranking, the more important the evaluation factor is, and the greater the weight corresponding to it.

(3) Quantifying non-logistics relationships, that is, the closeness of non-logistics relationships is determined by the score.

This article numbers the evaluation factor as i, so if there is a numbered evaluation factor between two job units, the job unit pair gets a weighted score numbered. The evaluation factors are divided into positive factors and negative evaluation factors. Positive evaluation factors indicate that there is a positive correlation between the two operation units, on the contrary, negative evaluation factors indicate that there is a negative correlation. For example, if two operation units are determined to be as far away as possible, i.e. do not want to be related, there is a negative correlation [4]. And negative evaluation factors and positive evaluation factors are completely mutually exclusive, that is, when there are negative evaluation factors between the two operating units, all of positive factors are not considered any more. Assuming that the evaluation factor $j$ is negative, the score of the operation unit pair with negative evaluation factor scored as: $Z_{\mathrm{k}-\mathrm{i}}=\mathrm{b}_{\mathrm{j}}$. 


\section{THE STATUS QUO AND PROBLEM ANALYSIS}

\subsection{General Features}

This warehouse is a material warehouse for a furniture factory that is used to store raw materials, semi-finished products and auxiliary materials for the manufacture of furniture products, and the items stored have the following characteristics:

(1) There are many kinds of articles, which are divided into raw materials and semi-finished products from the type of material production;

(2) The weight and size of the goods are not the same level, some of the commodity shape is large and not easy to move and need to occupy a larger space;

(3) Some of the raw materials are chemicals and are in danger of leakage.

(4) There are a variety of semi-finished products that need to be produced in the warehouse, and when receiving goods.

\subsection{Operation process analysis}

The entire process of inbound and outbound is shown at Figure 1and Figure 2.

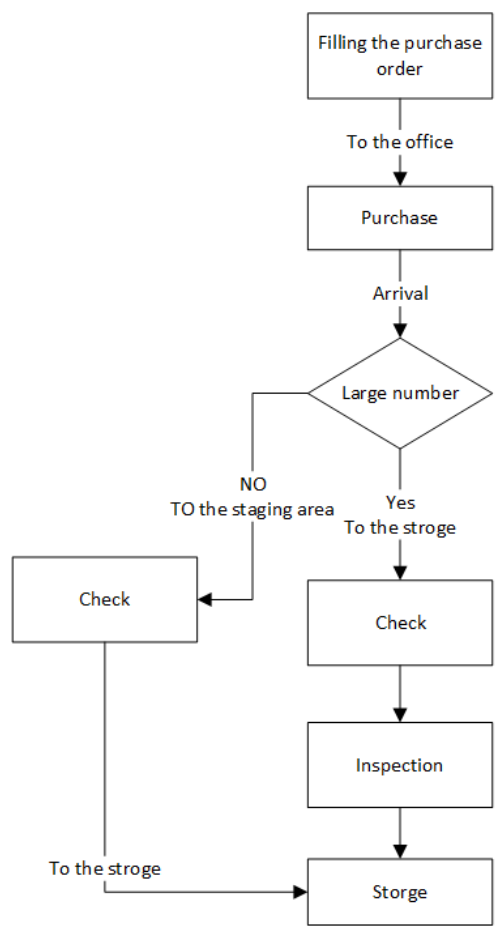

Figure1 THE INCOMING PROCESS

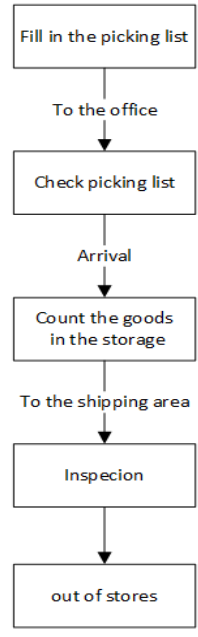

Figure2 OUTBOUND PROCESS

According to the operation process, the amount of logistics is assimilated between the warehouse operating units.

Table 1 VOLUME BETWEEN OPERATION UNIT

\begin{tabular}{|c|c|c|c|c|}
\hline start & end & logistics & Distance $(\mathrm{m})$ & $\begin{array}{c}\text { transport } \\
\text { volune }\end{array}$ \\
\hline Inbound zone & Storage & 871874 & 15 & 13078110 \\
\hline Inbound zone & Staging Area & 93862 & 3 & 281586 \\
\hline Staging Area & Storage & 93862 & 14 & 1314068 \\
\hline Staging Area & Return Zone & 2000 & 18 & 36000 \\
\hline Storage & Shipping Zone & 963736 & 10 & 9637360 \\
\hline
\end{tabular}

The operating unit logistics statistics table shows the incoming and storage areas and storage areas shipping areas of the largest amount of logistics, but the distance between the incoming and the storage area is 15 meters, and the distance between the storage area and the shipping area is 10 meters. Compared to other operating units, it may be a larger distance, which more makes the logistics volume greater between the operating units, increase discharging costs, and urgent need to improve.

\section{IMPROVEMENT PROCESS}

\subsection{Logistics analysis of operating units}

\begin{tabular}{|c|c|c|}
\hline Nunter & Nasle & Area (n) \\
\hline 1 & Inbound Zone & 12 \\
\hline 2 & Staging Area & 70 \\
\hline 3 & Logs storage & 130 \\
\hline 4 & Seni-finished & 90 \\
\hline 5 & Auxiliary material & 40 \\
\hline 6 & Return zone & 30 \\
\hline 7 & Shipping Zone & 30 \\
\hline 8 & Office & 50 \\
\hline
\end{tabular}

Figure3 AREA PER OPERATION UNIT 


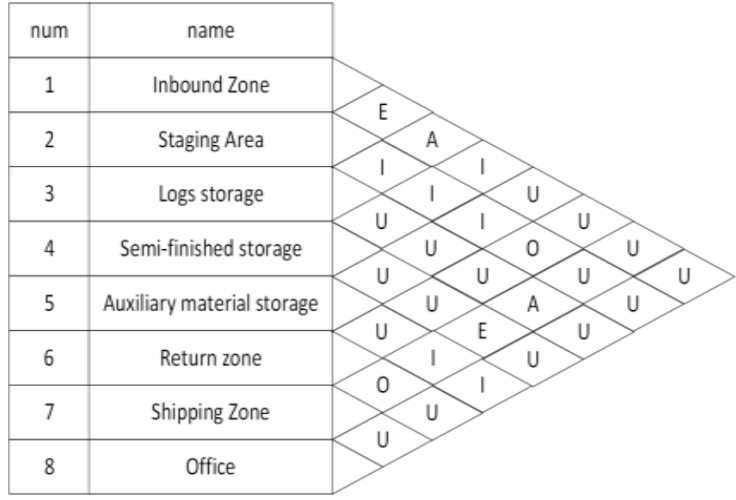

Figure4 WORK UNIT LOGISTICS-RELATED DIAGRAMW

\subsection{Quantitative analysis of non-logistics of operating units}

According to the problems reflected in the above warehouse and then combined with the actual situation, the following evaluation factors are determined.

\begin{tabular}{|c|c|c|}
\hline Num & Evaluation factors & weight \\
\hline 1 & Process continuity & $b_{1}$ \\
\hline 2 & $\begin{array}{c}\text { Contact between } \\
\text { workers }\end{array}$ & $b_{2}$ \\
\hline 3 & $\begin{array}{c}\text { Easy supervision and } \\
\text { managem ent }\end{array}$ & $b_{3}$ \\
\hline 4 & Use the same device & $b_{4}$ \\
\hline 5 & Safety and pollution & $b_{5}$ \\
\hline
\end{tabular}

Note: $b_{1}+b_{2}+b_{3}+b_{4}+b_{5}=1$

The above five evaluation factors are prioritized by 10 staff members, and then the evaluation factors are assigned according to the results of prioritization. Table 4-6 below ranks the results for 10 staff priorities.

Table 2 STAFF SCORE SHEET

\begin{tabular}{|c|c|c|c|c|c|}
\hline Person & Fac1 & Fac2 & Fac3 & Fac4 & Fac5 \\
\hline Staff1 & 2 & 1 & 4 & 5 & 3 \\
\hline Staff2 & 1 & 2 & 3 & 5 & 4 \\
\hline Staff3 & 4 & 1 & 2 & 5 & 3 \\
\hline Staff4 & 3 & 1 & 4 & 5 & 2 \\
\hline Staff5 & 3 & 1 & 4 & 5 & 2 \\
\hline Staff6 & 4 & 2 & 3 & 5 & 1 \\
\hline Staff 7 & 2 & 1 & 4 & 5 & 3 \\
\hline Staff8 & 4 & 1 & 3 & 4 & 2 \\
\hline Staff 9 & 1 & 2 & 4 & 5 & 3 \\
\hline Staff 10 & 1 & 2 & 3 & 4 & 4 \\
\hline Average & 2.5 & 1.4 & 3.4 & 4.8 & 2.7 \\
\hline Priority & 2 & 1 & 4 & 5 & 3 \\
\hline veigh & 0.23 & 0.32 & 0.17 & 0.09 & 0.19 \\
\hline
\end{tabular}

Based on the weight of the evaluation factors in the table above, the degree of correlation between units is calculated. If there is a relationship between the two operating units, then in addition to the evaluation factor 5 (safety and pollution) count-1, the rest of factors are 1, multiplied by the corresponding weight, and finally add the results, the final degree of association.

\section{Table3 JOB UNIT INTERRELATION}

\begin{tabular}{|c|c|c|c|c|c|c|c|c|}
\hline End & Unit & unit & Unit & Unit & unit & Unit & unit & unit \\
start & 1 & 2 & 3 & 4 & 5 & 6 & 7 & 8 \\
\hline Unit1 & & 124 & 4 & 4 & & & & 12 \\
\hline Unit2 & & & & 4 & 4 & 13 & & \\
\hline Unit3 & & & & 4 & & & 1 & \\
\hline Unit4 & & & & & & & 1 & \\
\hline Unit5 & & & & & & & 1 & 5 \\
\hline Unit6 & & & & & & & 13 & 13 \\
\hline Unit7 & & & & & & & & 2 \\
\hline Unit8 & & & & & & & & \\
\hline
\end{tabular}

Note: The table uses 1, 2, 3, 4, 5 to represent the evaluation factors. When there is a relationship numbered 5 (safety and pollution) between two units, it does not take into account whether there are other evaluation factors between the two work units.

Table 4 SCORE TABLE ON THE INTERRELATION BETWEEN JOB UNITS

\begin{tabular}{|c|c|c|c|}
\hline $\begin{array}{c}\text { unit pair } \\
\text { Staging }\end{array}$ & $\begin{array}{c}\text { Score } \\
0.09=0.64\end{array}$ & $\begin{array}{c}\text { unit pair } \\
\text { Shipping }\end{array}$ & 0.23 \\
\hline $\begin{array}{c}\text { Inbound \& } \\
\text { Logs }\end{array}$ & 0.09 & $\begin{array}{c}\text { Semi- } \\
\text { finished } \\
\text { \&Shipping }\end{array}$ & 0.23 \\
\hline $\begin{array}{c}\text { Inbound } \\
\text { \&Semi- } \\
\text { finished }\end{array}$ & 0.09 & $\begin{array}{c}\text { Auxiliary \& } \\
\text { Shipping e }\end{array}$ & 0.23 \\
\hline $\begin{array}{c}\text { Inbound \& } \\
\text { office }\end{array}$ & $0.23+0.32=$ & $\begin{array}{c}\text { Auxiliary } \\
\text { \&office }\end{array}$ & -0.19 \\
\hline $\begin{array}{c}\text { Staging } \\
\text { \&Semi- } \\
\text { finished }\end{array}$ & 0.55 & $\begin{array}{c}\text { Return } \\
\text { \&Shipping } \\
\text { Zone }\end{array}$ & $0.23+0.17=$ \\
\hline $\begin{array}{c}\text { Staging } \\
\text { \&Auxiliary }\end{array}$ & 0.09 & $\begin{array}{c}\text { Return } \\
\text { \&Office }\end{array}$ & $0.23+0.17=$ \\
\hline $\begin{array}{c}\text { Staging \& } \\
\text { Return }\end{array}$ & $0.23+0.17=$ & $\begin{array}{c}\text { Shipping } \\
\text { \&Office }\end{array}$ & 0.42 \\
\hline $\begin{array}{c}\text { Logs \& } \\
\text { Semi- } \\
\text { finished }\end{array}$ & 0.4 & - & - \\
\hline
\end{tabular}

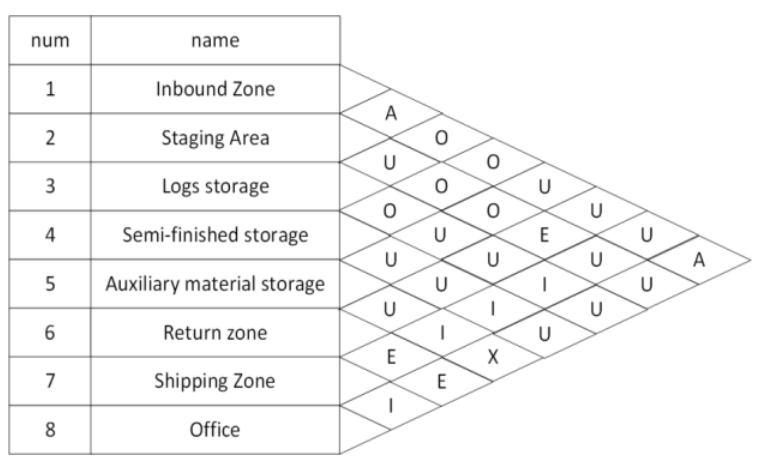

Figure5 NON-LOGISTICS-RELATED DIAGRAM OF OPERATING UNITS 


\subsection{Integrated interrelationships}

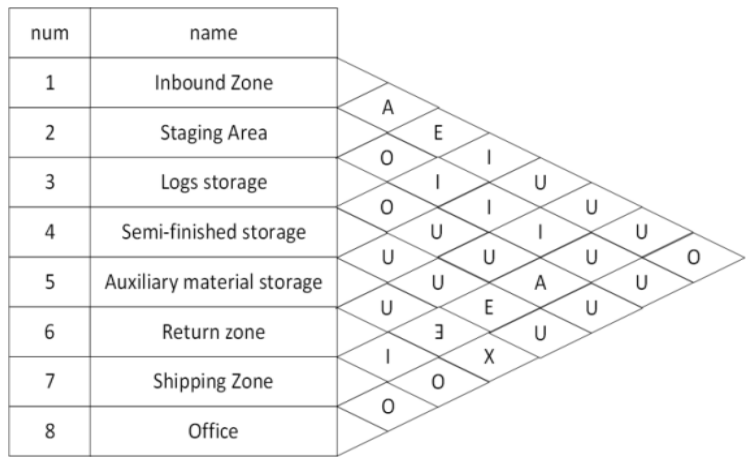

Figure 6 WORK UNIT COMPREHENSIVE CORRELATION

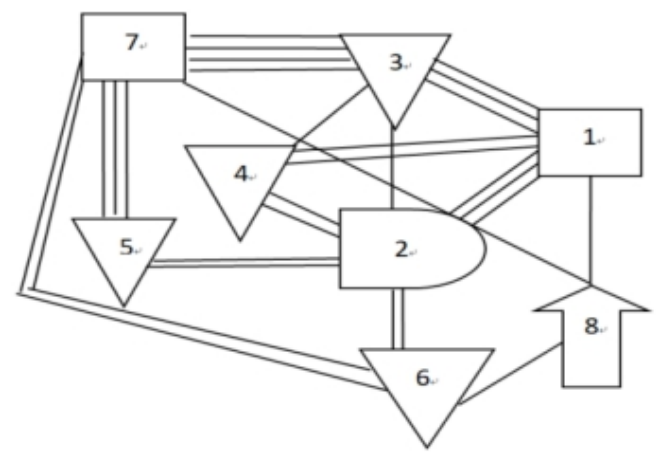

Figure7 OPERATING UNIT LOCATION-RELATED

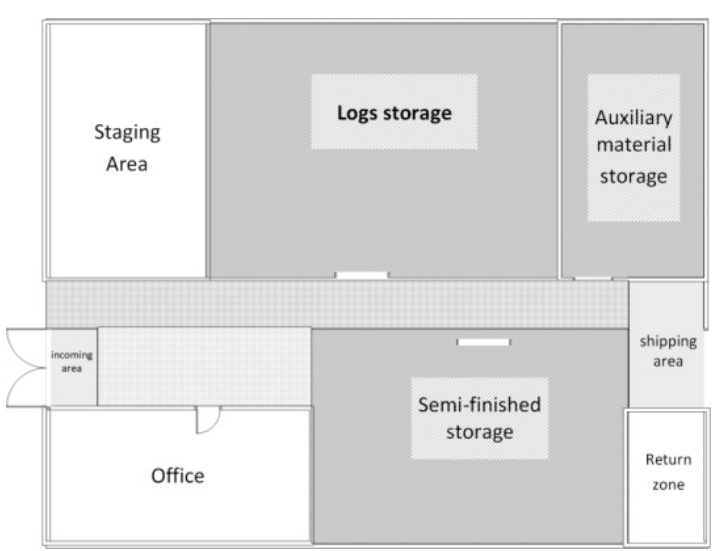

Figure 8 SCENARIOI

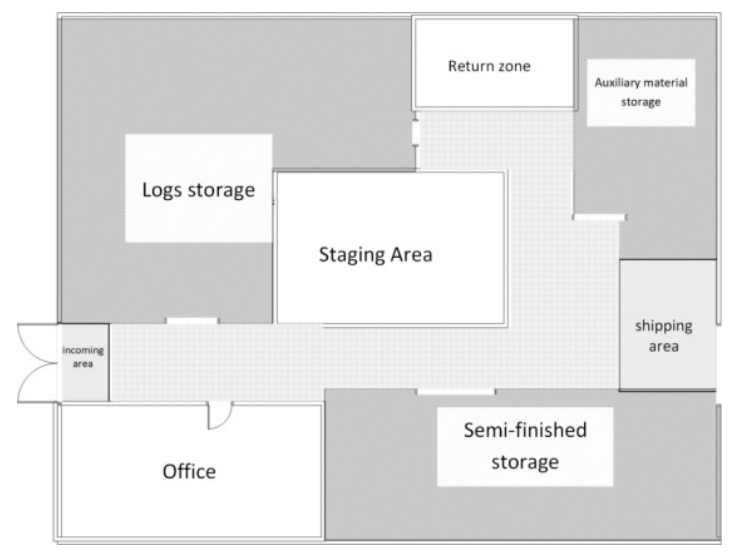

Figure 9 SCENARIOII

\section{CONCLUSIONS}

Firstly, the current situation of furniture material warehouse was carried out a detailed investigation and the basic situation and the operation process analysis, which found that there are low handling efficiency and low efficiency problems. According to the actual situation, this paper analyzed the root cause of its production is that the warehouse operating unit layout is unreasonable.

Secondly, owing to the SLP method is too subjective, it proposes an improvement scheme for the SLP method. This improvement is that by analyzing the regional logistics relationship of the warehouse unit and quantifying the non-logistics relationship, we can obtain the comprehensive interrelation, and then draw the relevant map of the position of the work unit, and finally draw several possible optimization schemes.

Due to the limited personal capacity and other factors, there is still space for improvement in this paper. For example, when drawing a plan, it still mainly rely on the scenario-makers, so still have to doped into the subjective ideas.

\section{ACKNOWLEDGMENT}

During my writing, my teachers and classmates have given great help in both academic and life, and have given me support when I encounter difficulties. Here, I sincerely express my gratitude to them.

\section{REFERENCES}

1. P. C. Pandey, S. Janewithayapun, M. A. A. Hasin. An integrated system for capacity planning and facility layout[J]. Production Planning \& Control, 2000, 11(8).

2. Wenhao Yu, Tinghua Ai. The visualization and analysis of urban facility pois using network kernel density estimation constrained by multi-factors[J]. Boletim de Ciências Geodésicas, 2018, 20(4)

3. Wu Yujiao, Zhu Lingyao, Wu Yue. Logistics Facilities Planning and Design Based on SLP. 2016, 2(3)

4. Ying Wang, You Rong Li, Yu Qiong Zhou. Research on the Facilities Layout Planning in MTO Manufacturing Industry Based on Genetic Algorithm. 2014, 2864:695-702. 